\title{
Welfare Inequality in Nigeria
}

\section{Osunde Omoruyi}

\author{
Department of Sociology and Anthropology, University of Benin, Benin City, Nigeria \\ E-mail: oosunde@gmail.com
}

\section{Kingsley Ufuoma Omoyibo (Ph.D.)}

Department of Sociology and Anthropology, University of Benin, Benin City, Nigeria Email: ufuomaomoyibo@hotmail.com

\section{Doi:10.5901/mjss.2014.v5n7p579}

\section{Abstract}

\begin{abstract}
Using National Living Standard Survey (NLSS) 2004 to analyse the distribution of income and expenditure to analyse welfare inequality measure Nigeria. We compare the income and expenditure indicators to ascertain which affects welfare mostly. We observed that income index affect individual welfare than expenditure. Although we identify the limitation of both measures, however, using Generalised Entropy Class of Inequality measures to determine welfare inequality. We found out that welfare inequality in Nigeria stems from differences among households with similar measured characteristics, rather than between groups. In regard to the decomposition by population characteristics, our inequality measures age-group of household heads, family composition and educational level of heads of household as important factors in explaining inequality sources. Using the regression-based decomposed methods, we decompose household sources of income inequality into contributions by individual deterministic factors plus the shares by the residual term. We found that, based on the GE (2) decomposition, among the deterministic factor, household farm income was by far the most significant single contributor to household income inequality in Nigeria.
\end{abstract}

Keywords: Consumption Approach, Household, Income Approach, Inequality, Welfare

\section{Introduction}

The effect of the distribution of income on individual welfare remains a debated question in economics and other related discipline. This research area is where strong normative judgements outweigh the existing empirical findings. It however depends on the interpretation that one is given to it. For instance some see inequality as a sign of opportunity and or rewards to productivity; it is difficult to accept that there are negative effects. For those that see inequality as a reflection of persistent disadvantage for particular segments of society, it is hard to see positive elements. And for those who are primarily concerned with the fostering of income growth, and perhaps with the reduction of absolute poverty, inequality is beside the point.

According to Addison and Cornia (2001) relative income differences matter to individual welfare, and in ways relevant to economic decision. The relative income differences matter in two ways. The first one is the level effect. This is where two individuals of the same level of income perceive themselves differently if the average wealth of their relevant peer group is different. The second is the adaptation effect: as people's incomes rise so do their expectation. Thus it takes more income to increase their utility the same amount than when their income was at a lower level.

Another aspect of inequality we have limited knowledge of is inequality per se - inequality defined more broadly than in terms of personal incomes on individual welfare. Young (1995) asserted that the concept of inequality should be looked beyond income disparity or inequality between groups, among neighbours and within and across skills and education cohorts. It also involve norms of equality and views about fairness and redistribution, which vary across cultures and societies

However, measuring accurately this broader aspect of inequality is a conceptual and empirical challenge. Access to micro data in analysing the evolution of welfare and inequality overtime in Nigeria is another major problem. The lifecycle hypothesis of consumption argues that provided individuals can borrow and lend, temporary reductions in income need have no effect on consumption. Analysing consumption patterns in this case may provide a more accurate picture of permanent inequality than focusing on income alone. 
As a result of this we will use both income and consumption indicators as a welfare measure to examine the demographic effect on individual welfare. Both income and consumption indicators are relatively not often used by researchers to measure inequality and also little studies have been carried out on the level of inequality in Nigeria. Therefore, this study tends to contribute to the existing literature on economic development by examining inequality by population share, relative mean income and within sub-groups for age group of household heads, family composition, as well as the educational level of the heads of household. The contribution of household sources of inequality was also determined using the regression base decomposition method.

An extensive literature examines the effects of inequality on aggregates growth outcomes, such as incentive for working and saving. These studies suggest that inequality can have perverse effects on aggregate welfare. Even there are mixed results. Barro (2001) finds that inequality is bad for economic growth for countries with per capita GNP'S below $\$ 500$ but good for growth for countries with GNP'S above that level. Addison and Cornia (2001) and Kanbur and Lustig (1999) find that income inequality has risen in many developing countries including Nigeria. They asserted that it will have negative impact on individual welfare. They also agreed with Birdsall et al, $(1995,1997)$ assertion that increasing inequality has negative effects on growth for developing countries, operating via channels such as initial asset endowments, savings rates, investment and in education.

On the consumption side, Akita et al, (1999) for instance used consumption data in identifying the factors responsible for welfare inequality in Nigeria. They included urban-rural disparity, educational attainment level of household heads, age distribution, gender and regional differences. A study by Canagarajah et al, (1997) reported increased level of poverty over the period spanning the 1980s and 1990s in Nigeria using the consumption data. Their findings revealed an increased in the Gini coefficient from 38.1 in 1985 to 44.9 percent in 1992 respectively.

A similar study conducted by Okojie et al, (2001) used relative poverty lines based on some percentage of mean per capita consumption to identify the poor and found that between 1992 and 1996 poverty in Nigeria increased from 43 percent to 69 percent. On the income side, Oyekale et al (2006) compared rural and urban household inequality in Nigeria using income information and posited that as of 2004, income inequality is higher in rural than urban areas. Adams and Jane (1995) also examine the sources of income inequality and poverty in Rural Pakistan using income data. Their findings revealed that two income sources nonfarm and live-stock tend to decrease inequality overall inequality, while the other three source - agricultural, transfers and rental will increase overall inequality.

In a paper by Bhalla (2003) reported that both urban and rural Gini coefficients declined between 1993-1994 and 1999-2000. According to his calculation, rural inequality decreased in 15 out of 16 major states in India, and urban inequality declined in 8 of the 17 states over this period. Contrarily, regional disparities are high and increasing especially in Africa continent. For example Sahn and Stifel (2003) in Africa; Escobal and Torero (2003) in Latin America; and Friedman (2005) in Asia; reported in their various studies that regional inequalities are high, and they have been rising. Frawley et al. (2000) assess the factors underlying the emergence of the low-income farm households and the effectiveness of farm income and general welfare policies in countering the lack of viability of the farm sector. They found that low-income farm households were distributed evenly throughout the state and were found to be closely associated with small farms and dry stock farm systems. They also find however those low income farm households are no more deprived than the average of all households in the state.

Other studies from Awoyemi, (2004) and Kaija (2007) reported that non-farm income sources has grown substantially during the last two decades and its share to total household income ranges between $30 \%$ and $50 \%$ in some developing countries. In this respect, the behaviour of rural households in diversifying their sources of income and employment from solely agriculture to non agricultural activities could be considered to be important as critical requirements for reducing inequality in Nigeria

There are some potential problems associated with using both income and expenditure as a measure of welfare inequality. It is well known that expenditure on certain commodities such as alcohol and cigarettes tend to be under reported in expenditure survey. Also, household expenditure over a short period of time may differ from household consumption, which is the variable of interest (see Alayande 2003).

On the income, Wilkinson, (1986) is of the opinion that any methods that focus only on income present narrow view of inequality as they do not accounts for disparities in health, mortality, living standards, nutrition and social status across income groups in the society. Haig-Simons added to this assertion that most income measure omits job satisfaction, extra market production and foregone income takes leisure and accrue capital gain are usually not part of income measured. Table 1 further present the advantages and disadvantages of using income and consumption approach to welfare measures. All other indicators such as job satisfaction is beyond the scope of this study. Nevertheless we believe that a more complete picture of welfare inequality in Nigeria can be obtained by comparing both income and expenditure measure together. 
Table 1: Consumption and Income Approach to Welfare

\begin{tabular}{|l|l|}
\hline \multicolumn{1}{|c|}{ Advantages } & \multicolumn{1}{|c|}{ Disadvantages } \\
\hline $\begin{array}{l}\text { 1) Easy to measure income, given the limited } \\
\text { number of sources of income }\end{array}$ & 1) Likely to be under-reported \\
\hline $\begin{array}{l}\text { 2) Measure degree of household command over } \\
\text { resources }\end{array}$ & $\begin{array}{l}\text { 2) May be affected by short-term fluctuation e.g. (seasonal pattern of } \\
\text { Agriculture). }\end{array}$ \\
\hline $\begin{array}{l}\text { 3) Cost only a fifth as much to collect as } \\
\text { expenditure data, so sample can be higher }\end{array}$ & $\begin{array}{l}\text { 3) Some parts of income are hard to observed e.g. informal sector income; } \\
\text { home agricultural production; self-employment income. }\end{array}$ \\
\hline & 4) Link between income and welfare is not always clear \\
\hline \multicolumn{1}{|c|}{ Consumption approach to welfare } \\
\hline & $\begin{array}{l}\text { 1) Rousorting period might not capture the "average" income of the } \\
\text { social reforms). }\end{array}$ \\
\hline 1) Shows current actual standard of living & $\begin{array}{l}\text { 2) Consumption choices made by household may be misleading (e.g. if a } \\
\text { rich household chooses to live simply) }\end{array}$ \\
\hline $\begin{array}{l}\text { 2) Smoothes out irregularities and so reflects } \\
\text { long term average well-being }\end{array}$ & 3) Some expenses are not incurred regularly so data may be noisy \\
\hline $\begin{array}{l}\text { 3) Less-understated than income because is } \\
\text { easier to recall }\end{array}$ & $\begin{array}{l}\text { 4) Difficult to measure some components of consumption, including durable } \\
\text { goods. }\end{array}$ \\
\hline
\end{tabular}

Source: Albert, 2004 and Ahmed 2007

The rest of this study proceeds as follows; discussion of the methodology and data used in estimating the level of household inequality in Nigeria. After which the analysis of the results are presented and we then concludes.

\section{Methodology}

From the vast literature on inequality, we can sum up the available methodologies into three main approaches. First is the axiomatic approach. This involves identifying a number of desirable conditions or axioms, inequality measurement ought to follow. The approach uses indicators such as the mean logarithmic of deviation, income weighted Theil and half squared coefficient of variation, all belonging to the Generalised Entropy GE (a) class of inequality measures. The general formula of the Generalised Entropy Class of Inequality measures is given by

$$
\mathrm{GE}(\alpha)=\frac{1}{\alpha^{2}-\alpha}\left[\frac{1}{n} \sum_{i=1}^{n}\left(\frac{y_{i}}{\bar{y}}\right)^{\alpha}-1\right]
$$

Where the $y$ 's are the individual incomes and $\bar{y}$ is the arithmetic average in a population of $\mathrm{n}$ individuals. If $\mathrm{a}=1$ then we have equal weighting ratios. If $a<1$ then the lower income groups become more important in the overall measurement.

The three typical values of $\alpha$ in empirical research are zero, one, and two, and these values result in the following three measures of inequality:

$$
\begin{aligned}
& \text { Mean log deviation GE }(0)=\frac{1}{n} \sum_{i=1}^{n} \operatorname{In}\left(\frac{\bar{y}}{y_{i}}\right) \\
& \text { Theil Index GE }(1)=\frac{1}{n} \sum_{i=1}^{n}\left(\frac{y_{i}}{\bar{y}}\right) \operatorname{In}\left(\frac{y_{i}}{\bar{y}}\right)
\end{aligned}
$$

GE (2) is half of the square of the coefficient of variation =

$$
\frac{1}{\bar{y}}\left[\frac{1}{n} \sum_{i=1}^{n}\left(y_{i}-\bar{y}\right)^{2} \mid\right]^{1 / 2}
$$
coefficient.

One other measure that is widely used in looking at inequality is the Lorenz curve based measure; the Gini

$$
\text { Gini }=\frac{1}{2 n(n-1) y} \sum_{i=1}^{n} \sum_{j=1}^{n}\left|y_{i}-y_{j}\right|
$$


Second is the social welfare approach which followed in the Atkinson $\left({ }^{\mathrm{A}_{e}}\right)$ index. The Atkinson Index is an inequality measures that clearly incorporates normative judgements about social welfare (Atkinson 1970). The index is derived by calculating the so-called equity-sensitive average income $\left(\mathrm{A}_{e}\right)$, which is defined as that level of per capita income, which if enjoyed by everybody would make total welfare exactly equal to the welfare, generated by the actual income distribution. The equity-sensitive average income is given by:

$$
\mathrm{A}_{\boldsymbol{\epsilon}}=\left(\sum_{i=1}^{n} f\left(y_{i}\right) y_{i}{ }^{1-\epsilon}\right)^{1 /(1-\epsilon)}
$$

Where $y_{i}$ is the proportion of total income earned by the ith group and $e$ is the so-called inequality aversion parameter. The parameter e reflects the strength of society's preference for equality and can take values ranging from zero to infinity. When $e>0$, there is a social preference for equality (or an aversion to inequality). As e rises, society attaches more weight to income transfers at the lower end of the distribution and less weight to transfers at the top. Typically used values of e include 0.5 and 2 .

The Atkinson index (I) is then given by:

$$
\mathrm{I}=1-A_{i} / \bar{y}
$$

Where $\bar{y}$ is the actual mean income or consumption. The more equal the income distribution, the closer ${ }^{A_{e}}$ will be to ${ }^{\bar{y}}$, and the lower the value of the Atkinson index. For any income distribution the value of I lies between 0 and 1 .

The approaches emphasises the importance of using the statistical inference and sampling variance. For example in the case of social welfare functions, if one has to make a conclusive comparison between the inequality levels of distribution we need to see the statistical significance of our results. Usually we will be required to examine the standard errors of our estimates.

One of the main axioms that inequality measurements are required to meet is that of decomposability. The measures mentioned above under the GE class can be decomposed for across, between and with-in group inequality in an additive manner, but the Gini coefficient in equation 4 cannot (see Shorrocks, 1980). For example to decompose the Mean Log Deviation Index (i.e. GE (0) see equation 2), let $Y$ be the total income of the population, ${ }^{{ }_{j}}$ the income of a sub-group, $N$ the total population, and ${ }^{N_{j}}$ the population in the sub-group using $L$ to represent $G E(0)$.

$$
\mathrm{L}=\sum_{i=1}^{N} \frac{1}{N} \ln \left(\frac{Y}{Y, N}\right)=\sum\left(\frac{N j}{N}\right) L_{j}+\sum_{j} \frac{N j}{N} \operatorname{In}\left[\frac{N_{j} / N}{Y_{j}} \mid\right]
$$

The first term of the above equation represents the within-group inequality and the second term represents the between-group inequality. Such decomposition can make it difficult to see the influence of continuous variable such as the age. As the decomposition by population groups is dependent upon the sample size and in the case of a large number of categories the calculation map become very cumbersome. Keeping in view these issues a regression-based method has also been developed for inequality decomposition to measure welfare (see Fields and Yo0, 2000).

The method starts with a decomposition of total income or consumption $Y$, into a regression equation as detailed in formula (8)

$$
\mathrm{Y}=\mathrm{X} \beta+\varepsilon
$$

Where $\mathrm{Y}$ is an $\eta \times \mathrm{M}$ vector of attributes and $\varepsilon$, and $\eta^{\mathrm{X}} 1$ vector of residuals. The next step involves splitting for each unit i, total income into the component ${ }^{Y_{i}^{m}}$, accounted for by each independent variable $\beta_{i}$, as defined:

$$
\mathrm{Y}_{i}=\sum_{m=1}^{m+1} Y_{i}^{m}
$$

For $\mathrm{M}=1 \ldots \mathrm{M}(9)$

Where $\mathrm{Y}_{i}^{m}=\mathrm{X}_{i}^{m} \beta^{m}$,

For $\mathrm{M}=\mathrm{M}+1$

$\mathrm{Y}_{i}^{m}=\varepsilon_{i}$,

Instead of using a decomposition method for population group, we then use a decomposition method for income characteristics. Inequality is broken up into the 'absolute factor contribution' $S f$

$$
\mathrm{I}=\sum_{f} s f=\sum_{f} I p_{f} \chi_{f} \sqrt{\mathrm{II}_{f}}
$$


Where $p_{f}$ is the correlation between component $f$ and the total income and $\chi_{f}=u_{f} / u$ is factor $f^{\prime}$ factor share.

It is necessary to employ an inequality index that is robust to the existence of Zero income such as I2, half the squared coefficient of variation, $\left(\sigma^{2} / 2 \mu^{2}\right)$ see Jenkins, (1995).

\section{Data}

The data used for this study is from the Nigerian Living Standard Survey (NLSS) 2004. The data is an annual survey of a sample of incomes expenditure, labour market status and demographic information collected by the National Bureau of Statistics (NBS) ${ }^{1}$ Nigeria. It is designed to collects information related to incomes, expenditures, demographics and labour market status as its primary objective. One of the main objectives of the National Living Standard Survey is to determine the poverty and inequality situation in Nigeria by measuring the level of the distribution of resources among individuals and households. The sample size is randomly selected from 120 housing units from each state and the Federal Capital Territory (FCT, Abuja) called Enumeration Areas (EAs). The data set for our analysis comprises of a sample of 92610 individuals and 19158 households representing the total population that participated in the survey at any time during the period. The concept of income used in this study includes income earned both in cash and in-kind and is solely based on the determination of earnings.

To obtain our total household disposable income, we had to aggregate and subsequently annualised the various sources of income (such as employment income + self employment income + farm income + capital income + benefits taxes). All these aggregated incomes tend to measure welfare. On consumption, we aggregated and annualised food and non-food expenditure including imputed own produce and other budget shares. In order to compare the welfare of the inhabitants of different households, we used modified OECD equivalence scales.

\subsection{Summary Statistics}

Table 1 highlights some summary statistics for average age of household heads, household size, all adults in the household and persons over 65 years of age living in the household. It is evident from Table 1 that the average age of the household from the data survey appears to be reasonably estimated. The household groups are constructed on the basis of the number of person per household. It can be seen that the average age for a single person in the household is 37 years. The highest number of persons in the household is households with married couples having more than two other adults and more than two children living, accounting for 9.6 persons.

The percentage of adults age 16 to 64 in the population accounted for 46 percent, lower than children 0 to 15 years of age at 51 percent. The proportion of the population over 65 years is only 3 percent. Interestingly, most household groups with the highest number of children are single parent with children (group 3 and 8) followed by those married coupled with children household (group 5, 6 and 10). The high rate in the proportion of children is likely to have increased the amount of income or consumption of a child-rearing household.

Table 1: Average Age of Household head, Number of persons per Household and the proportion of All Adults, children and persons over 65 years old in each Household Group

\begin{tabular}{cccccc}
\hline Group & Average Age of Household Head & Number of Person per Household & Adult ${ }^{2}$ & $65+3$ & Child $^{4}$ \\
\hline 1 & 37 & 1.0 & 100 & 0 & 0 \\
2 & 73 & 1.0 & 0 & 100 & 0 \\
3 & 47 & 4.1 & 20 & 4 & 76 \\
4 & 46 & 2.0 & 87 & 13 & 0 \\
5 & 42 & 5.6 & 34 & 2 & 64 \\
6 & 52 & 5.9 & 68 & 6 & 26 \\
7 & 60 & 4.8 & 88 & 12 & 0 \\
8 & 48 & 6.4 & 46 & 4 & 50 \\
9 & 49 & 3.1 & 91 & 9 & 0
\end{tabular}

\footnotetext{
1 For detailed information about the NLSS, go to www.nigerianstat.gov.ng/NLSS 2004 dataset.

${ }^{2}$ Adults means individuals aged 16 to 64

365 plus refers to adults 65 years or older

${ }^{4}$ Child is those individuals under 16 years old
} 


\begin{tabular}{cccccc}
10 & 49 & 9.6 & 42 & 3 & 55 \\
11 & 77 & 3.4 & 0 & 57 & 43 \\
12 & 61 & 2.9 & 33 & 67 & 0 \\
\hline Total & 48 & 6.5 & 45.8 & 3.4 & 50.8 \\
\hline
\end{tabular}

Note: $1=$ single person without children; 2 = single old person; 3 = single with children; 4 = married couple no children; $5=$ married couples with children; $6=$ married more than two adults with children; $7=$ married more than two adults with no children; $8=$ unmarried couples with children; $9=$ unmarried with no children; $10=$ married more than two adults and more than two children; 11 = married old couple; 12 = others. Source: Calculations based on National Living Standard Survey data weighted to represent the entire household population

\subsection{Result 1: inequality in nigeria}

The common inequality indicators discussed above can be used to assess the major contributors to inequality, by different subgroups of the household population as well as by income sources. The results in Table 4 to 6 show the population shares and the relative mean income and expenditure of each sub-group by age group, household groupings and educational attainment of the household heads. The nearer the inequality measure is to zero the more equal the distribution of household income and expenditure within each subgroup.

Table 2 provides statistics summarizing the extent of equality in the distribution of household income and expenditure. We present eight alternative measures of dispersion commonly used in the inequality literature. These measures differ in their sensitivity to changes throughout the distribution. In particular, the 75/25 percentile ratio and coefficient of variation are sensitive to changes in the tails of the distribution and the Gini coefficient is sensitive to transfers in the middle of the distribution. All of these measures indicate higher inequality in household income than expenditure.

Table 2: Nominal Household Market Income Equality by Distribution Indicator

\begin{tabular}{lcc}
\hline Indicators & Income & Expenditure \\
\hline $\mathrm{CV}$ & 1.459 & 1.062 \\
Gini & 0.601 & 0.468 \\
Atkinson $\mathrm{a}=0.5$ & 0.274 & 0.155 \\
Atkinson $\mathrm{a}=1$ & 0.525 & 0.293 \\
Atkinson $\mathrm{a}=2$ & 0.978 & 0.528 \\
$75 / 25$ percentile Ratio & 5.882 & 3.175 \\
Mean Log Derivation & 0.745 & 0.346 \\
Theil Index & 0.584 & 0.336 \\
\hline
\end{tabular}

Source: Calculations based on National Living Standard Survey data weighted to represent the entire household population.

Table 3 presents the Gini inequality index for total household expenditure and income sources. The Gini index for Total Household Income is 0.601 , which implies that income inequality is high in Nigeria. Among the income sources, Farm Income source has the lowest Gini $(0.792)$, while Benefits record the highest inequality $(0.991)^{5}$. On the expenditure, the Gini index for total expenditure is 0.468 .

Table 3: Gini-Inequality Indices by Expenditure and Income Sources in Nigeria

\begin{tabular}{|l|c|}
\hline Income Sources & Gini Coefficient \\
\hline Total Household Income & 0.601 \\
\hline Total Household Expenditure & 0.468 \\
\hline Employment Income & 0.914 \\
\hline Self- employment Income & 0.843 \\
\hline
\end{tabular}

\footnotetext{
5 The calculated Gini coefficients are in line with the World Bank (2003) estimation for income gini coefficient of 0.613 in 1998; Aboyade (1974) 0.580; Oyekale et al, (2006) 0.580 for total household income; 0.885 for employment income; 0.698 for farm income; 0.845 for self-employment income; 0.975 for capital income and 0.994 for benefits. On the expenditure side, National Bureau of Statistics reported 0.488 Gini coefficients.
} 


\begin{tabular}{|l|l|}
\hline Farm Income & 0.792 \\
\hline Capital Income & 0.912 \\
\hline Benefits & 0.991 \\
\hline
\end{tabular}

Source: Calculations based on National Living Standard Survey data weighted to represent the entire household population.

\subsection{Result II: Decomposing Inequality By Population Group in Nigeria}

There is a close association between the age structure and the distribution of income among people, because the size and composition of personal incomes from work, capital and transfer vary during the life cycle. As Barr (1993) puts it, "household income usually increases gradually with age of the household head until a certain age. After reaching a peak, it starts to decline". Table 4 reveals that the relative mean income and expenditure of household age groups. The result shows that respondents aged 45-54, 55-64 and above 65 years is higher than the average mean income and expenditure of other household age-groups. Surprisingly age group 25-34 years have the lowest relative mean household income and expenditure. One of the suggested reasons is that economic crisis of the 1980s eroded income and purchasing powers and left many young people unemployed. Hence most of the individual within age group 25-34 were in their primes and the crisis negatively affected their income status at the period of reference.

As can be seen from Table 4, the sub-group inequality is higher among the households whose household heads' falls within the age groups with the highest mean income and expenditure. The population share of this age group is also high. The subgroup inequality for age group below 25 years is as high as 58 percent for household income and 45 percent for expenditure. The high inequality index for the household headed by individuals whose age is below 25 and 25-34 years old are more than that of individuals just entering into the labour market. As they grow older, however, inequality reduces and it not surprising that by age group 45-54, inequality has reduced for income and increased in expenditure. Further decreases prevail at 55-64 and 'greater than 65' age groups for expenditure than household income.

Our decomposition analysis indicates that most of the welfare inequality can be traced to within group component as this represents more than 99 percent of total inequality. This reveals that the disparity between age-group is not significant in overall inequality. The significance of the finding is that age is not an important determinant factor in explaining inequality among households. The bulk of the inequality still exists between households headed by individuals of the same age group.

Table 4: Population Shares, Relative Incomes and Expenditure and Inequality by Age Group of Household Heads

\begin{tabular}{|c|c|c|c|c|c|c|}
\hline Age group & $<24$ & $25-34$ & $35-44$ & $45-54$ & $55-64$ & $>65$ \\
\hline \multicolumn{7}{|c|}{ Income } \\
\hline Population Shares & 0.168 & 0.016 & 0.156 & 0.257 & 0.245 & 0.155 \\
\hline Relative Mean Household Incomes & 0.935 & 0.906 & 0.926 & 0.961 & 0.963 & 1.273 \\
\hline Subgroup Inequality & 0.585 & 0.510 & 0.559 & 0.546 & 0.566 & 0.582 \\
\hline \multicolumn{7}{|c|}{ Expenditure } \\
\hline Population Shares & 0.166 & 0.019 & 0.151 & 0.255 & 0.244 & 0.162 \\
\hline Relative Mean Household Incomes & 1.018 & 0.749 & 0.803 & 1.005 & 1.054 & 1.105 \\
\hline Subgroup Inequality & 0.446 & 0.417 & 0.424 & 0.448 & 0.413 & 0.403 \\
\hline
\end{tabular}

Source: Calculations based on National Living Standard Survey data weighted to represent the entire household population.

Table 5 shows that for income single-parent household heads without children, inequality is higher. The share of the population in these groups is very small. This is a complete contrast with consumption household with similar household group. However, sub-group inequality is also higher for household with a couple and more than two children in consumption than income. The most striking feature that emerges from Table 5 is that over three-quarters of total inequality are due to within-group inequality. This has important implications for policies targeted at specific groups which treat all members of these groups equally. They will do little to reduce inequality because they fail to tackle the large degree of inequality within a particular group. 
Table 5: Population Shares, Relative Incomes and Expenditure and Inequality by Household Groupings of Household Heads

\begin{tabular}{ccccccc}
\hline & \multicolumn{3}{c}{ Income } & \multicolumn{2}{c}{ Expenditure } \\
\hline Household Group & Pop Shares & Rel. mean Incomes & Subgroup Inequality & Pop Shares & Rel. mean Expenditure & Subgroup Inequality \\
\hline 1 & 0.025 & 0.815 & 0.552 & 0.023 & 0.259 & 0.273 \\
2 & 0.002 & 0.616 & 0.326 & 0.003 & 0.455 & 0.173 \\
3 & 0.036 & 0.703 & 0.559 & 0.035 & 0.710 & 0.332 \\
4 & 0.014 & 0.616 & 0.491 & 0.016 & 0.521 & 0.341 \\
5 & 0.207 & 0.982 & 0.542 & 0.227 & 0.888 & 0.427 \\
6 & 0.101 & 1.100 & 0.570 & 0.105 & 0.998 & 0.429 \\
7 & 0.027 & 1.227 & 0.588 & 0.026 & 0.959 & 0.386 \\
8 & 0.248 & 0.921 & 0.575 & 0.201 & 0.983 & 0.394 \\
9 & 0.038 & 0.831 & 0.592 & 0.034 & 0.667 & 0.396 \\
10 & 0.295 & 1.118 & 0.571 & 0.323 & 1.241 & 0.425 \\
11 & 0.001 & 1.370 & 0.518 & 0.002 & 1.339 & 0.383 \\
12 & 0.000 & 0.792 & 0.000 & 0.000 & 0.969 & 0.021 \\
\hline
\end{tabular}

Note: $1=$ single person without children; 2 = single old person; 3 = single with children; 4 = married couple no children; $5=$ married couples with children; $6=$ married more than two adults with children; $7=$ married more than two adults with no children; $8=$ unmarried couples with children; $9=$ unmarried with no children; $10=$ married more than two adults and more than two children; 11 = married old couple; 12 = others.

Source: Calculations based on National Living Standard Survey data weighted to represent the entire household population.

There is a substantial literature documenting the increase in the return to education in both developed and developing countries. Studies have also shown that the level of education is low in developing countries and Nigeria is no exception. Table 6 shows a positive relationship between educational attainment of the household head and the per capita mean income and expenditure. We found the higher the educational attainment for the head of the household, the higher the relative mean income and consumption. The sub-group inequality also increases with educational attainment on the consumption side and is higher for those household heads with lower secondary education for income.

In the context of the above decomposition in Table 6, we find that there is an increase in between-group inequality among all the factors of inequality that is considered in this study. This shows that in addition to inequality within educational level of the household heads, differences in educational level attained by the household heads also accounts for inequality among Nigerian households. The implication is that although, household heads may have attained the same educational level, their incomes or expenditure are largely determined by their employment activities. These activities subsequently further determine the structure of earnings differences and thus mean average income and expenditure.

Table 6: Population Shares, Relative Incomes and Expenditure and Inequality by Educational attainment of Household Heads

\begin{tabular}{|c|c|c|c|c|c|}
\hline Education & No edu & Primed & Losec & Upsec & Univ \\
\hline \multicolumn{7}{|c|}{ Income } \\
\hline Population Shares & 0.366 & 0.049 & 0.220 & 0.187 & 0.175 \\
\hline Relative Mean Household Incomes & 0.978 & 1.093 & 1.006 & 0.839 & 1.181 \\
\hline Subgroup Inequality & 0.555 & 0.539 & 0.594 & 0.535 & 0.573 \\
\hline \multicolumn{7}{|c|}{ Expenditure } \\
\hline Population Shares & 0.361 & 0.049 & 0.231 & 0.188 & 0.168 \\
\hline Relative Mean Household Incomes & 0.760 & 1.036 & 1.051 & 1.081 & 1.343 \\
\hline Subgroup Inequality & 0.420 & 0.400 & 0.389 & 0.408 & 0.447 \\
\hline
\end{tabular}

Note: No edu = No formal education; Primed = primary; Losec = Lower secondary; Upsec = Upper secondary; Univ = University

Source: Calculations based on National Living Standard Survey data weighted to represent the entire household population. 


\subsection{Result III: Decomposing Inequality By Income Source in Nigeria}

In table 7, reports the contribution of the entire deterministic factor to sources of income inequality for household income heads based on the GE (2) decomposition using the regression based decomposition method. The decomposition of contributors to income inequality by the residual term, the constant term, and all non-constant $\mathrm{X}_{s}$ are carried out on four sources of household income. The results we observed in household group for instance that the GE (2) value of 159.13 is higher relative to that if other household groups. Household group 4 has a GE (2) value of 60.81 . This suggests that inequality within group is much higher for married couples with more than two adults without children (group 7) than for all of the other groups. Farm Income is by far the most significant contributor to household income inequality in Nigeria. The absolute factor contribution is +159.13 for farm income and -0.32 for capital income. This shows that capital income works towards reducing inequality within the group. The importance of capital income towards overall inequality is insignificant in most household groups.

Table 7: GE (2) and Absolute Factor Contribution for each Income Sources (Decomposition for Nigeria)

\begin{tabular}{c|ccccc}
\hline Group & $\mathrm{GE}(2)$ & Employed & Self-employed & Farm Income & Capital Income \\
\hline 1 & 76.69 & 15.64 & 60.27 & 0.22 & 0.56 \\
2 & 18.64 & 0.00 & 10.67 & 0.85 & 7.12 \\
3 & 77.96 & 24.95 & 12.18 & 41.11 & -0.32 \\
4 & 60.81 & 10.34 & 28.93 & 20.97 & 0.57 \\
5 & 86.47 & 6.00 & 2.58 & 77.03 & 0.86 \\
6 & 117.38 & 5.72 & 1.10 & 110.27 & 0.30 \\
7 & 159.13 & 43.20 & 4.43 & 111.43 & 0.08 \\
8 & 105.66 & 4.56 & 2.02 & 98.89 & 0.19 \\
9 & 69.50 & 12.93 & 24.66 & 28.22 & 3.69 \\
10 & 111.03 & 2.06 & -0.02 & 108.80 & 0.19 \\
11 & 44.88 & 0.00 & -1.12 & 41.50 & 4.51 \\
12 & 2.64 & 0.00 & 0.13 & 2.51 & 0.00 \\
\hline Total & 101.32 & 6.49 & 3.92 & 90.39 & 0.51 \\
\hline
\end{tabular}

Note: 1= single person without children; 2 = single old person; 3 = single with children; 4 = married couple no children; 5 = married couples with children; $6=$ married more than two adults with children; $7=$ married more than two adults with no children; $8=$ unmarried couples with children; $9=$ unmarried with no children; $10=$ married more than two adults and more than two children; 11 = married old couple; 12 = others.

Source: Calculations based on National Living Standard Survey data weighted to represent the entire household population.

\section{Conclusion}

This study used the National Living Standard Survey (NLSS) 2004 to analyse the issue of welfare inequality in Nigeria employing both income and expenditure measures. At the aggregate level, the striking result which emerges is the dissimilarity of income and expenditure distribution. Household income measures indicate a higher inequality measure than consumption. A more detailed analysis of welfare inequality in Nigeria stems from differences among households with similar measured characteristics, rather than between differences between groups. In regard to the decomposition by population characteristics, our inequality measures age-group of household heads, family composition and educational level of heads of household as important factors in explaining inequality sources. However, we found that most of the inequality exists within group and not much of the differences in groups explain appreciable levels of inequality in Nigeria except for education of household heads. Using the regression-based decomposed methods, we decompose household sources of income inequality into contributions by individual deterministic factors plus the shares by the residual term. We found that, based on the GE (2) decomposition, among the deterministic factor, household farm income was by far the most significant single contributor to household income inequality. 


\section{References}

Adams, R.H. and J. Jane (1995), Sources of Income Inequality and Poverty in Rural Pakistan, Research Report 102 Int. Food Policy Research Institute 17(2) 80 ISBN: 0-89629-105-7. http://.ifpri.org/reports/0695RPT/0695BHTM

Addison and Cornia (2001). Income Distribution Policies for faster poverty Reduction. WIDER Discussion Paper No. 2001/93, World Institute for Development Economic Research.

Aigbokhan, B.E. (2008), "Growth, Inequality and Poverty in Nigeria", Economic Commission for Africa, ACGS/MPAMS Discussion Paper No.3

Akita, T. R. A. Lukman and Y Yamada (1999) Inequality in the Distribution of Household Expenditure: A Theil Decomposition Analysis The Developing Economics 37(2) 197-221

Atkinson, A.B., (1970). "On the Measurement of Inequality". Journal of Economic Theory 2: 244-263.

Awoyemi, T. T. (2004): Rural Non-Farm and Poverty Reduction in Nigeria. A Report submitted to AERC, Nairobi, Kenya.

Alayande, B.A. (2003) Decomposition of Inequality reconsidered: Some evidence from Nigeria. Paper presented to the UNU/WIDER conference on Inequality poverty and Human well being.

Barr N; 1993. The Economics of the welfare state $2^{\text {nd }}$ Edition. London weidenfeld and Nicolson

Barro, R (2001). "Inequality, Growth and Investment", in K.A. Hasselt and R.G. Hubbard, eds; Inequality and Tax Policy, AEI Press.

Bhalla, S. (2003). Recounting the Poor: Poverty in India, 1983-99. Economic and Political weekly, 25-31 January: 338-349

Birdsall, N. Ross, D. and Sabot, R. (1995). "Inequality and Growth Reconsidered", World Bank Economic Review, Vol. 9 (September), pp. 477- 508,

Birdsall, N. and Juan, L. (1997). "Asset Inequality Matters: An Assessment of the World Bank's Approach to Poverty Reduction". American Economic Review, Vol. 87 (May).

Canagarajah, S. J., Ngwafon and S. Thomas (1997) "The evolution of poverty and welfare in Nigeria, 1985-92" Policy Research Working Paper No. 1715

Cowell, F.A., (1977) "Measuring Inequality". Oxford: Philip Allan Publishers.

Escobal, J. and M. Torero (2005) "Adverse Geography and differences in welfare in Peru" In Ravi Kanbur and Anthony Venable (eds), Spatial Inequality and Development. Oxford University Press. January.

Friedman, J. (2005) "How Responsive is Poverty to Growth? A Regional Analysis of poverty, Inequality and Growth in Indonesia, 198499" In Ravi Kanbur and Anthony Venable (eds), Spatial Inequality and Development. Oxford University Press. January.

Frawley, J., P. Commins, S. Scott and F. Trace, (2000). "Low Income Farm Households: Incidence, Characteristics and Policies", Dublin: Oak Tree Press

Field, G.S. and G. Yoo (2000), Falling Labour Income Inequality in Korea's Economic Growth: Patterns and Underlying Causes. Review of Income and Wealth 46: 139-159.

Jenkins, S. (1995). "Accounting for Inequality Trends: Decomposition Analysis for the UK, 1971-86". Economica, Vol. 62, pp. 26-63

Kanbur, R. and N. Lustig (1999). Why is Inequality Back on the Agenda? Paper prepared for the Annual Bank Conference on Development Economics, World Bank Washington DC April 28-30

Kaija, D. (2007): Income Diversification and Inequality in Rural Uganda: The Role of Non-Farm Activities. A paper prepared for the Poverty reduction, Equity and Growth Network (PEGNeT) Conference, Berlin, September 6-7, 2007.

NBS (2004), "Nigeria Living Standard Survey", National Bureau of Statistics, Statistics Division, Government of Nigeria, 2004.

Okojie, C.E. Anyanwu, J.C., Oguwmike F.O., and B.A. Alayande (2001) Nigeria: Gender Dimension, Access to Social Services and Labour Market Issues" Final Report of Collaborative Research Study on Poverty, Income Distribution and Labour Market Issues Submitted to the African Economic Research Consortum, Nairobi Kenya.

Oyekale, A.S, A.I., Adeoti and T.O. Oyekale, (2006) Measurement of Sources of Income Inequality in Rural and Urban Household in Nigeria. Poverty and Economic Policy Network Working Paper, University laval, Canada pp.12-21

Peyton Young (1995) Equity: In theory and practice (Princeton: Princeton University Press, 1995)

Sahn, D and D. Stifel (2003). "Urban-Rural Inequality in Living Standard in Africa". Journal of Africa Economics Vol. 12, Number 1 December, pp. 564-597.

Shorrocks, A.F.(1984) Inequality decomposition by population subgroups Econometrica 52(6), 1369-88

Wilkinson, R.G., (1986b), "Income and Mortality" in R.G. Wilkinson (ed), Class and Health) (Tavistock publication, London), pp. 88114.

World Bank (2006) 'Nigeria Country Brief'. Washington: World Bank.http://web.worldbank.org 